\title{
The Moderators and Mediators of Door-in-the-Face Requests: Is it a Negotiation or a Helping Experience?
}

\author{
Monique Mitchell Turner, Ron Tamborini, \\ M. Sean Limon, \& Cynthia Zuckerman-Hyman
}

The Door-in-the-Face (DITF) compliance-gaining tactic occurs when a large request, expected to be rejected, is followed by a more reasonable request that is granted. The mechanisms underlying the DITF strategy remain unclear. Researchers have posed different explanations for the effectiveness of DITF, including the reciprocal concessions and the social responsibility models. These theoretical rationales for DITF were tested in a 3 (request type: initial request only, DITF sequence, small request only) $\times 2$ (initial request size: moderate, large) $\times 2$ (solicitor familiarity: friend, stranger) betweenparticipants experiment. Findings from the compliance data are mostly consistent with the reciprocal concessions model; but, findings from the cognitive and affective data were mixed. It appears that DITF messages are perceived as a helping situation for friends, but not for strangers. Strangers view request messages of all sizes to be a negotiation, but friends see these requests as a negotiation only when the initial request is large.

Keywords: Compliance; Sequential Request Strategies; Door-in-the-face; Reciprocal Concessions; Guilt

Persuasion scholars have long believed that an effective compliance-gaining tactic is to begin by making a large request, with the expectation that it will be rejected, and follow its refusal with a smaller request (Cialdini et al., 1975). This approach, the Door-in-the-Face (DITF) sequential request strategy, has received considerable

\footnotetext{
The first and second author contributed equally to this manuscript, thus the order of authorship was determined on the basis of a coin flip. Monique Mitchell Turner (PhD, 1999, Michigan State University) is Associate Professor at the University of Maryland, College Park. Ron Tamborini (PhD, 1982, Indiana University) is Professor at Michigan State University. M. Sean Limon (PhD, 2000, Michigan State University) is Assistant Professor at the University of Florida, and Cynthia Zuckerman-Hyman (MA, 1997, University of Georgia) is a lecturer at North Carolina State University. The authors want to express their gratitude to Ed Fink for his insight into this manuscript. Correspondence to: Monique Turner, 2105 Skinner Building, College Park, MD 20742-7635, USA. E-mail: mmturner@umd.edu
} 
attention since the seminal study by Cialdini and his colleagues. The effectiveness of the DITF strategy is evidenced by meta-analyses (Dillard, 1991; Dillard, Hunter, \& Burgoon, 1984; Fern, Monroe, \& Avilla, 1986) as well as many primary studies. Research indicates effect sizes of the tactic ranging between $r=.15$ and $r=.25$, before taking into consideration any possible moderating variables (Hale \& Laliker, 1999). Yet, there is no clear understanding of the cognitive and affective processes assumed to motivate compliance with the DITF method.

This investigation tests two possible explanations for the success of the DITF tactic: the reciprocal concessions and social responsibility models; each of which has underlying cognitive and/or affective mechanisms. ${ }^{1}$ A field experiment manipulating request type, relational familiarity, and initial request size was conducted to build on recent work attempting to map the psychological states experienced by receivers of DITF requests (Dillard \& Hale, 1992; O’Keefe \& Figge, 1997, 1999; Tusing \& Dillard, 2000). We examine predicted mediators and moderators assumed by each theoretical account.

\section{Theoretical Accounts for the DITF Strategy}

In 1975, Cialdini et al. conducted perhaps the first examination of the DITF tactic. Confederates were told to approach participants on a college campus and ask them if they were willing to spend two hours per week, for at least two years, donating time to a juvenile detention center. When this request was refused, as expected, it was followed up with a more reasonable request - to be chaperones for a group of juvenile delinquents on a two hour trip to the zoo. Cialdini et al.'s data were clear: The DITF request produced more compliance than the small request by itself. Also clear was that the success of this technique was due to the sequence of actions. In both the DITF and the small request conditions, the target request was the same: chaperone for two hours. Yet, rates of compliance increased when a larger request had already been rejected by the receiver. This begs the question: What happens, cognitively and affectively, to people when they reject a large request and are confronted immediately with a smaller request? We understand that DITF requests increase compliance (compared to a small request only), but we are still unclear on why they are effective.

The most commonly cited explanation for the DITF effect is the reciprocal concessions model (Cann, Sherman, \& Elkes, 1975; Cialdini et al., 1975); although in the last decade this rationale has been challenged with logic based on social responsibility (O’Keefe, 1999; O’Keefe \& Figge, 1997; Tusing \& Dillard, 2000). Regardless of which rationale is proposed, published studies on DITF have made few attempts to examine the experience of receivers during the DITF sequence in a manner that might illuminate some of the theoretical underpinnings suggested by different scholars. Initial research measured only compliance, comparing the effectiveness of a DITF message with a small request only (Cann et al., 1975; Cialdini et al., 1975). Subsequent research generally did not measure the underlying cognitive or affective mechanisms associated with explanations offered (Abrahams \& Bell, 1994; Patch, 
Hoang, \& Stahelski, 1997; Reeves, Baker, Boyd, \& Cialdini, 1991). For example, Goldman, McVeigh, and Richterkessing (1984) conducted an experiment testing three opposing theories supposedly accounting for the DITF effect, yet measured only compliance. Moreover, those few scholars who have measured mediating processes have limited their measures to the rationale favored, and have not included observations associated with alternative theoretical viewpoints (Bell, Abrahams, Clark, \& Schlatter, 1996; O'Keefe \& Figge, 1999). Notably absent from the extant research are observations taken after the initial request and prior to the second smaller request. This omission makes it difficult to assess cognitive processes during the sequence of requests thought to underlie different theoretical accounts. Without empirical evidence of mediators and moderators associated with both reciprocal concessions and social responsibility, any attempts to distinguish the theories are limited.

As a result, we have limited understanding of receiver perceptions after the initial request in the DITF routine, and we have inadequate evidence related to the underlying mechanisms of the two competing rationales. There is much to be gained by measuring perceptions as message receivers "travel" through the compliancegaining sequence. To accomplish this goal, people's perceptions, as well as compliance, after responding to a small request only, after receiving the initial request in a DITF sequence, and after responding to the full DITF sequence are measured. This method allows us to assess perceptions of the tactic after the initial request as well as after the full DITF sequence to illuminate any changes in affect or cognition. Moreover, by comparing perceptions at different points in the DITF sequence with a small request only, we can assess whether such perceptions are unique to the DITF message.

Admittedly, it is difficult to measure the processes proposed to mediate DITF effects. Most efforts to do this require scholars to assume that people can recollect the thoughts they had when messages were received. Although such an assumption is easily made in mindful interactions, it is a difficult assumption when interactions are more mindless (Langer, 1989; Langer, Blank, \& Chanowitz, 1978). It is unclear whether a DITF exchange is mindless. Langer et al. (1978) argued that most human behavior is mindless, but provided data suggesting that large requests inhibit mindlessness. As such, we might expect mindfulness to be promoted by the large request in DITF interactions and that recall of thoughts during the message sequence will be reasonably accurate. Nonetheless, we note the difficulty of measuring the cognitive and affective mediators of the DITF process. Due to these potential difficulties, we also examine compliance as a function of the moderators that distinguish the competing theories. Greater confidence will result if information gleaned from cognitive and affective mediators is consistent with the information provided by compliance measures. Overall, we believe that any effort to examine the theoretical mechanisms of DITF is important.

\section{Reciprocal Concessions}

Gouldner (1960) defined reciprocity as "a pattern of mutually contingent exchange"; and argued that reciprocity is a universal norm in human societies (p. 161). ${ }^{2}$ This 
definition suggests that reciprocal acts are normally required to fulfill obligations evoked by pre-giving. The reciprocal concessions explanation for DITF is based on the notion that individuals "give benefits to those who give them benefits" (Gouldner, 1960, p. 170).

Cialdini et al. (1975) offered reciprocal concessions as the explanation for the effectiveness of the DITF tactic. They argued that DITF sequences are similar to bargaining in that during a DITF sequence askers make a concession when they backoff from their first offer and make a more reasonable offer. Therefore, when receivers of DITF requests perceive that a concession has been made, they will feel compelled to reciprocate via complying. Tusing and Dillard (2000) also stated that the use of the term "concession" implies that DITF messages are a bargaining or negotiation interaction (Cialdini et al., 1975; Cialdini \& Ascani, 1976).

The bargaining literature provides several examples of reciprocal concessions. For instance, Komorita and Brenner (1968) conducted an experiment where they had one group of participants in a negotiation situation initially propose an equitable price and refuse to deviate from that price throughout the negotiation. In another experimental condition, the participants asked for a very high price and gradually lowered the price throughout the negotiation. Komorita and Brenner concluded that failing to make a concession in a negotiation, even if the first starting price is fair, is an ineffective strategy for reaching an agreement (see also Chertkoff \& Conley, 1967). Advocates of the reciprocal concessions explanation for DITF argue that the process is similar. If this logic is accurate, feelings of obligation and perceptions of a negotiation mediate the effect of DITF requests on compliance. ${ }^{3}$

In addition to mediators, the reciprocal concessions/negotiation explanation has implications for two moderators of DITF success that are inspected in this study: the initial request size and relationship familiarity. ${ }^{4}$ Examining these moderators may help us understand the mechanisms underlying DITF.

Initial request size. If the success of a DITF request is based on its perception as being a negotiation whereby receivers are obligated to reciprocate, then the initial request size should affect compliance. All else being equal, the second request in a DITF sequence should be seen as a greater concession as the size of the initial request increases. Moreover, given that it is the initial request that makes the second request appear to be a concession, the target should perceive greater obligation to comply when the initial request is large than when it is moderate. Cialdini et al. (1975) stated "... the size of the second favor must be unambiguously smaller than that of the first; only then can the action of a reciprocal concessions norm come into play" (p. 207). O'Keefe and Figge (1997) also noted that if the reciprocal concessions theory were valid, then rates of compliance would increase as the magnitude of the initial request increases (see also Mowen \& Cialdini, 1980).

Relational familiarity. If the DITF effect is explained by reciprocal concessions, familiarity between the communicator and receiver should also serve as a moderator, such that the DITF effect will be more robust for strangers than for friends. In fact, reciprocity has been observed between strangers who will never meet again and when no one will hear about the act (Fehr \& Gächter, 2000; Güth, Schmittberger, \& 
Schwarze, 1982). Diekmann (2004) showed that reciprocity between strangers remained robust even when stakes were high. Observing reciprocity in one-shot interactions, with high stakes and no one watching, demonstrates that the norm of reciprocity can be a powerful moral obligation for strangers in social interactions. Notably, however, patterns of reciprocity (i.e., how soon, how much, and how to reciprocate) seem to differ as a function of familiarity (e.g., Bar-Tal, Bar-Zohar, Greenberg, \& Hermon, 1977; Rook, 1987; Winn, Crawford, \& Fischer, 1991).

Clark and Mills (1979) distinguished the contexts of stranger and friend interactions as exchange and communal relationships, respectively. In exchange relationships, characteristic of strangers, favors are given with the expectation that they will be reciprocated. A principle of immediate reciprocity, or "tit-for-tat" reciprocity, underlies these interactions. By contrast, in communal relationships the giving of benefits is need-based and the receiving of benefits does not create an immediate obligation to reciprocate in kind. In associated research, Clark (1981) found that perceptions of relational closeness were influenced by reciprocity patterns. Participants were asked to read short narratives about two people in which one person provided a favor and the other reciprocated with either the same or a different type of favor. Participants rated the two people as closer when the favors they exchanged were different and less close when the type was the same. Shackelford and Buss (1996) found similar patterns in their data. They found that immediate reciprocity resulted in a stronger sense of betrayal among committed mates and friends than among coalition partners (who were rated as not close). These findings are consistent with research showing that norms of reciprocity (e.g., pregiving) enhance compliance for strangers but not for friends (Boster, Rodriguez, Cruz, \& Marshall, 1995).

Taken together, research on relational familiarity suggests that expecting reciprocation, reciprocating the same type of favor, and reciprocating immediately are negatively related to perceptions of closeness. ${ }^{5}$ As such, if the effectiveness of the DITF strategy over a small request only is explained by reciprocal concessions, then higher DITF compliance should be found when the initial request is large and the receiver is a stranger, where expectations of immediate reciprocation are stronger and perceptions of interactions as a negotiation are more likely. In sum, if the effectiveness of the DITF sequence is explained by reciprocal concessions, then obligation and perceptions that the interaction is a negotiation are important mediators, and relational familiarity and initial request size are important moderators of this effect.

Criticisms of the reciprocal concessions/negotiation explanation. Critics of the reciprocal concessions explanation have argued that it is not supported by the evidence (Abrams \& Bell, 1994; Dillard, 1991; Dillard et al., 1984; O’Keefe, 1999; O'Keefe \& Figge, 1997, 1999). Although meta-analyses indicate that the DITF effect is heterogeneous (O'Keefe \& Hale, 1998), there is no evidence that initial request size serves as a moderator (Fern et al., 1986; O'Keefe \& Hale, 1998) — which is in contrast to reciprocity predictions. Notably, not all scholars agree with these meta-analytic findings (Hale \& Laliker, 1999). Hale and Laliker (1999) argued that studies using 
overly large initial requests may have induced an incredulity effect - which would account for why very large first requests often proved ineffective in DITF studies. Also, evidence regarding the moderating role of relational familiarity is lacking in the literature because, with few exceptions (see Tusing \& Dillard, 2000), DITF research has not varied familiarity. This omission has resulted in the exclusion of familiarity as a possible moderator in meta-analyses (Dillard, 1991; Dillard et al., 1984). The offshoot of all this is that regardless of present criticisms of the reciprocal concessions explanation (Cialdini, 1984, 1993; Pratkanis \& Aronson, 2001), some still view it as a viable explanation for the DITF effect, and others posit alternative theoretical underpinnings such as social responsibility.

\section{Social Responsibility}

Tusing and Dillard (2000) argued that DITF interactions are perceived more as a helping situation than as a negotiation situation. The social responsibility model assumes that individuals "possess a notion of social responsibility, and to varying degrees ... endorse it” (p. 8). According to Berkowitz and Daniels (1963), social responsibility is an internalized standard that guides individuals' behavior. Applied to DITF requests, perceiving the initial request as a helping situation activates the social responsibility standard resulting in heightened perceptions that deserving others are in need of help. When the first request is rejected, failure to meet the social responsibility standard acts as a guide for responding to the smaller second request. As such, the perception that the request is a helping situation mediates the relationship between the DITF request and compliance.

Using scenarios created to represent different compliance gaining situations, Tusing and Dillard (2000) found that participants judged helping concepts as more relevant to DITF interactions than bargaining concepts, and rated a DITF message more similar to interactions in which friends or strangers were confronted with a helping request than with a bargaining request. Although these findings are consistent with social responsibility logic, the measures were judgments of hypothetical DITF requests made to others, and not the reactions of actual participants in a DITF request sequence. Tusing and Dillard stated that valuable information can be gathered by conducting research where people are actually a part of a DITF request. This way, instead of guessing what they would do, participants are reporting what actually happened.

The social responsibility model has implications for the feelings people experience in a DITF sequence; based on the belief that when people turn down the initial request, they feel guilty for not helping and do not want to refuse to help again. Thus, their feelings of guilt motivate them to comply with the second request in order to alleviate their negative feelings (O'Keefe \& Figge, 1997, 1999). O'Keefe and Figge also argued that people will comply to the second request in a DITF sequence because they expect they will feel even worse if they do not comply. Models including affective mediators are assumed to be very complex. O'Keefe and Figge (1997) argued that guilt itself, like other emotions, is very complicated, stating "It should be plain that our guilt-based account depicts DITF effects as extraordinarily delicate and complex" 
(p. 74). Tusing and Dillard (2000) posited that the social responsibility model is consistent with the proposal that guilt is the proximal cause for the DITF effect. They noted that receivers perceive the solicitation as a helping request, and feelings of guilt arise when refusal of the first request makes salient their failure to meet the social responsibility to help. Indeed, guilt has long been thought to increase compliance (Boster et al., 1999; Wallace \& Sadalla, 1966). Tusing and Dillard view the social responsibility and guilt positions as two pieces of the same puzzle. The two explanations differ in that social responsibility highlights necessary preconditions for the DITF, "whereas guilt emphasizes the process responsible for the DITF" (p. 9). Hence, one difference between the social responsibility, model and the reciprocal concessions model concerns the point in the DITF sequence when perceptions become salient. According to reciprocal concessions, people perceive a negotiation to be occurring (and feel obligated) after the concession has occurred (i.e., after the second request). According to social responsibility, the perception of helping occurs after the initial request. Saying no to that request makes people feel badly and therefore more compliant. By examining perceptions during the sequence of DITF request, we can attempt to differentiate these models. Moreover, by examining these perceptions after a small request only we can examine if these affective and cognitive reactions are unique to a DITF message. Next, we turn to the moderating variables assumed by the social responsibility model.

Relational familiarity. If DITF messages are more effective than a small request due to social responsibility, then DITF requests should be more compelling to friends than to strangers. Extant literature supports the notion that individuals are more compliant with helping requests from friends than from strangers (Cialdini \& Trost, 1998; Clark, Ouellette, Powell \& Milberg, 1987; Frenzen \& Davis, 1990; Williamson \& Clark, 1992), and several explanations for this effect are consistent with social responsibility logic. For example, whereas agreeing to helping requests from friends creates positive feelings (Williamson \& Clark, 1992), refusing these requests leads to the type of negative affect that comes from failure to meet obligations, and might even endanger relationships (Williamson, Clark, Pegalis, \& Behan, 1996). According to Clark et al. (1987), familiarity is an important determinant for feelings of obligation. Though receiving benefit does not create an obligation to reciprocate among friends (Clark \& Mills, 1979), people feel a responsibility to close others. In the words of Burger, Soroka, Gonzaga, Murphy, and Sommervell (2001), "there are many reasons to believe that we are more likely to agree to a request from someone we know and like than from someone we do not know or do not like." (p. 1578). As such, we expect familiarity to affect helping because the initial request is viewed as a call for help; and individuals are more likely to help friends. Of course, this still implies a DITF effect because the failure to comply with the initial request makes helping more salient and increases guilty feelings.

Social responsibility also indicates that request size will not function as a moderating variable. If the request is viewed as an opportunity to be helpful, then it is unreasonable to assume that people want to help more if the initial request is large versus moderate. In other words, the size of the initial request should not 
enhance compliance for friends or strangers. In sum, this model holds that people will feeling guilty after saying no to an initial request; and, should feel less guilty after complying with a DITF request, regardless of initial request size.

\section{Predictions}

To encapsulate, the reciprocal concessions model holds that the DITF tactic is effective because when people turn down an initial request and have it followed by a more reasonable request they perceive they are in a negotiation situation and feel obligated to participate. Strangers are more likely to engage in direct reciprocation than are friends. Moreover, the larger the concession by the asker, the more likely receivers will comply due to greater obligation.

On the contrary, the social responsibility model predicts that when people are asked a first request of any kind they perceive a call for help. When individuals turn down this call for help, they feel badly and therefore are more compliant. Compliance relieves their feelings of guilt; and people are more likely to help their friends than they are to help strangers.

Hence, the reciprocal concessions model and the social responsibility model can first be distinguished by examining compliance patterns in the data. Both models assume that the DITF tactic is more effective than a small request only or an initial first request by itself (the DITF tactic depends on people refusing the first request). But, predictions regarding the effects of relational familiarity and initial request size change dependent upon the model advocated for. Note that since the overall assumption in this investigation is a main effect for request type such that a DITF message will be more effective than either the initial request alone or a small request alone, this assumption will be tested, but it is not listed as a hypothesis.

$\mathrm{H} 1$ : If the reciprocal concessions model is the best fitting explanation for these data, then the greatest increase in compliance (i.e., the proportional gain in compliance computed as the ratio of percentage of compliance following a DITF request compared to percentage of compliance following a small request only [baseline]) will be found when the DITF request is delivered to a stranger and the size of the initial request is large.

$\mathrm{H} 2$ : If the social responsibility model is the best fitting explanation for these data, then the greatest increase in compliance (i.e., the proportional gain in compliance computed as the ratio of percentage of compliance following a DITF request compared to percentage of compliance following a small request only [baseline]) will be found when the DITF is delivered to a friend (regardless of initial request size).

These models can also be differentiated by examining perceptions of the cognitive and affective mediators presumed to underlie the reciprocal concessions as well as social responsibility models.

H3: If the reciprocal concessions model is the best fitting explanation for these data, request type, relational familiarity, and initial request size will interact to affect perceptions such that when the request type is DITF, the initial request size is large, and the receiver is a stranger (a) perceptions that the 
request is a negotiation will be greatest and (b) feelings of obligation will be greatest.

H4: If the reciprocal concessions model is the best fitting explanation for these data, DITF message effectiveness will be mediated by (a) the perception that the request is a negotiation, and (b) feelings of obligation.

H5: If the social responsibility model is the best fitting explanation for these data, relational familiarity will have a main effect on perceptions of the request as a helping situation such that friends will perceive the request as a helping situation more than will strangers.

H6: According to the social responsibility model, feelings of guilt will be positively correlated with compliance.

H7: If the social responsibility model is the best fitting explanation for these data, DITF message effectiveness will be mediated by (a) perceptions that the request is a helping situation and (b) feelings of guilt.

\section{Method}

\section{Participants}

Participants were 300 residents of a medium sized Midwestern city, who were approached by trained confederates that were unaware of the hypotheses. The confederates were volunteers for a charity named Bowling for Scholars - A Strike Against Cancer (BFS). Two-hundred and seventy-eight of the 300 participants agreed to fill out the questionnaire. Some responses were returned with no experimental condition marked on their packet, rendering that information useless; leaving usable 256 cases. Female participants made up $57.3 \%$ of the final sample. The mean age of this sample was 26 years $(S D=9.56)$. Fifty-two percent of the sample self-reported that at the time of the study they had also recently donated money to other fundraisers, with an average donation of $\$ 2.47(S D=\$ 1.53)$ to those charities. Eighty-six percent of the participants had never heard of BFS, and $64.7 \%$ were fulltime students at the time of the study.

Analyses were also undertaken to assess if there were systematic differences between friends and strangers. Thus, we assessed the age, sex, donation history, and student status of friends versus strangers with a chi-square analysis. Friends were more likely to be full time students ( $77 \%$ vs. $66 \%$ of the strangers), $\chi^{2}=4.57, p<.05$. Otherwise, there were no notable differences between the observed and expected frequencies for each variable, indicating no major demographic differences between the friends and strangers in this study.

\section{Design and Procedure}

The charitable requests were made on behalf of BFS. A 3 (request type: initial request, DITF request, small request) $\times 2$ ( size of initial request: moderate vs. large) $\times 2$ (solicitor familiarity: friend vs. stranger) independent groups factorial design was employed. The "small request only" could not be crossed with initial request size; therefore there were 10 experimental conditions. This study received institutional review board approval. 


\section{M. M. Turner et al.}

Fifty trained confederates (volunteers for the nonprofit charity event) who were blind to hypotheses were trained to deliver the door-to-door requests. Multiple confederates were used to minimize confederate effects and rule out potential between group differences due to one "good" confederate. The expected outcome of this is twofold. First, multiple confederates should increase confidence in the ecological validity of the results. Second, this technique should introduce more random error in delivery of requests, and thus reduce the likelihood of our finding predicted patterns in the data (i.e., produce a more conservative test of our hypotheses). Confederates were students in a fundraising class who participated for course credit. They learned about door-to-door fundraising and sequential request strategies in class. Following a lesson on door-to-door fundraising, they were told about the task (the experiment) and sent home with instructions regarding the procedures. Thereafter, one full class period (90 minutes) was used to train the confederates how to deliver the messages in a natural manner and the importance of consent and debriefing. To minimize bias as much as possible, confederates were not told the rationale for the study or the specific hypotheses forwarded.

Each confederate was assigned to make six solicitation attempts. To randomize the conditions among the confederates, researchers developed one packet of materials (the message and questionnaire) to represent each desired participant in each experimental condition and randomly distributed them among the confederates. Each packet had a random grouping of six (of the 10 possible) experimental conditions.

In the training session, confederates were broken into teams of two people and asked to practice delivering their lines to each other. Also, each confederate had to deliver the lines to the authors of this study. Confederates completed training when lines were delivered accurately and naturally (confederates needing additional help received private training from one of the researchers). For the stranger condition solicitations, each confederate was assigned a neighborhood within the city that the university is located in (to decrease the likelihood of participants being approached more than once). In all cases, confederates were told to include nonstudent respondents. Confederates were not allowed to collect data on campus (though, notably, the neighborhoods in which confederates went door-to-door were often inhabited by university students). Participant responses were sealed so that their identities would remain anonymous to the researchers.

Confederates began by explaining their affiliation with the BFS fundraiser and then proceeded with the induction by asking participants to contribute to the charitable event. The solicitation followed a script for the assigned request type condition. In all conditions the request began with the following statement: "I'm working as a volunteer coordinator to help organize the charity bowling event." From here, the procedure varied according to experimental conditions. Confederates continued with one of three statements representing the large initial request ("We're really looking for volunteers to help with the event. It takes about 10 hours a week through the end of April. Would you be interested?"), the moderate initial request ("We're really looking for people to take part in our event. Participants need to raise at least $\$ 30.00$ in 
pledges and come bowl with us. Would you be interested?"), or the small request ("Since you can't participate [volunteer] would you like to sponsor me for the event? Any amount would be fine."). ${ }^{6}$ In the DITF conditions, the large or moderate request (if refused) was followed by the small request.

After participants responded to the final request, they were told that although BFS is a real charity, and no deception had occurred, that "we are also interested in how people perceive fundraising requests." At this point confederates asked participants if they would sign a consent form and fill out a questionnaire. After the final debriefing participants were informed that if they felt awkward donating money now that they knew we were also conducting an experiment, they could feel free to retract their donation.

\section{Instrumentation}

Five items formed the relational closeness induction check (e.g., "The person who made this request is a good friend to me"; $M=4.42, S D=1.77, \alpha=.98$ ). Five items formed the perceived initial request size induction check (e.g., "This is a large request"; $M=3.67, S D=2.28, \alpha=.94$ ). Four items measured perceived obligation (e.g., "I felt obligated to comply with this request at the time it was made"; $M=3.14$, $S D=1.42, \alpha=.93)$. Perceptions of a negotiation were measured by using five items (e.g., "I felt I was in a negotiation situation"; $M=2.99, S D=1.28, \alpha=.91$ ). Four items formed the perceived helping scale (e.g., "I thought I had a chance to help this person"; $M=4.15, S D=1.29, \alpha=.91$ ). Five items formed the perceptions of guilt scale (e.g., "Not complying with the first request made me feel guilty"; $M=3.05$, $S D=1.34, \alpha=.94){ }^{7}$ Finally, confederates coded for whether the participant agreed to the request (both the first and second request dependent on condition) and the amount the participant donated.

Confirmatory factor analysis performed on each scale revealed that these data were consistent with the proposed eight-factor model. Inspection of the factor loadings and errors generated from the discrepancy between the obtained and predicted correlations resulted in exclusion of one item from the helping scale and one item from the obligation scale. Each of these scales formed unidimensional solutions in which both checks for internal consistency and parallelism yielded statistically insignificant errors. Each scale was a seven-point Likert scale, ranging from "strongly agree" to "strongly disagree." For all participants, an average-scale score on each factor was computed.

\section{Tests for Mediation}

Hypotheses 4 and 7 both call for a test of mediation. To test for mediation, we employed Baron and Kenny's (1986) procedures. Therefore, we regressed (a) the dependent variable on the independent variable, (b) the mediating variable on the independent variable, and (c) both the dependent and the mediating variable on the independent variable. According to these procedures, mediation is demonstrated by meeting three criteria: (a) In the first equation, the independent variable affects the dependent variable. (b) In the second equation, the independent variable affects 
the mediating variable. (c) In the third equation, the mediating variable affects the dependent variable and the effect of the independent variable on the dependent variable is reduced from that observed in the second equation.

\section{Results}

\section{Induction Checks}

In order to assess the effectiveness of the initial request size induction, a 2 (friend, stranger $) \times 3$ (small request only, moderate initial request, large initial request) ANOVA was performed on perceived initial request size. Familiarity was included to rule out the presence of an interaction. A significant main effect for initial request size emerged, $F(2,252)=49.93, p<.01, \eta^{2}=.29$. No other significant effects emerged. Subsequent analyses using Tukey's HSD test indicated all means significantly different from each other at $p<.001$. Participants rated the small request only condition as the smallest request $(M=3.08, S D=1.29)$, the moderate request higher $(M=4.22$, $S D=1.61)$, and the large request $(M=5.50, S D=1.56)$ highest.

An ANOVA was also conducted to assess the effectiveness of the solicitor familiarity induction. In particular, relational closeness was examined as a function of solicitor familiarity (friend, stranger) and initial request size (small request only, moderate initial request, large initial request). A main effect for relational closeness, $F(1,252)=808.29, p<.01, \eta^{2}=.77$, emerged indicating the familiarity induction was effective. Participants rated their friends $(M=5.65, S D=1.36)$ as being closer to them than strangers $(M=1.60, S D=0.77)$. No interaction effects emerged.

Finally, we also examined the data to ensure the presence of a DITF effect. A binary logistic regression with request size (DITF, small request only) as the independent variable and compliance ("yes" $=1$, "no" $=0$ ) as the dependent variable revealed a strong DITF effect, $\chi^{2}(1)=12.69, \beta=1.20$, Nagelkere $R^{2}=.11$, Wald statistic $(1)=$ $12.05, p<.001$. In the DITF conditions, $60 \%$ of the participants complied with the request while those in the small request only condition complied $31 \%$ of the time. It is also worth noting that, as would be expected, the majority of people refused to comply in either of the initial request only conditions ( $6 \%$ complied).

\section{Tests of Hypotheses}

Hypotheses 1 and 2 provide predictions regarding patterns of increased compliance forecast by the reciprocal concessions and social responsibility models of DITF. According to the reciprocal concessions model (Hypothesis 1) the largest increase in compliance will be found when the DITF request is delivered to a stranger and the size of the initial request is large. According to the social responsibility model (Hypothesis 2) the largest increase in compliance will be found when the DITF is delivered to a friend (regardless of initial request size).

Table 2 contains the percentage of compliance for all experimental conditions as well as the increase ratios for the relevant comparison groups. This table reveals that the strangers complied with the small request $22.6 \%$ of the time and friends complied with the small request $39.4 \%$ of the time. These provide a baseline for strangers and 
friends respectively. Our question regards how much a DITF message can boost compliance as compared to a small request only (see Table 1). Fifty percent of strangers complied to the DITF request in both the moderate and the large initial request conditions (an increase in compliance from the small request only baseline of $121 \%$ in both cases). For friends, $73.7 \%$ complied in the DITF/large initial request condition (an increase of $87 \%$ ) and $69.6 \%$ complied in the DITF/moderate initial request condition (an increase of $77 \%$ ). Eyeballing the data, it appears that friends receiving a DITF message with a large initial request have the greatest compliance; but, the largest increase in compliance is with strangers who received a DITF message (regardless of the size of initial request). Whether these differences are statistically significant must be assessed.

First, a $\chi^{2}$ test on the differences between the small request only and the relevant comparison cells (DITF mod/DITF large) for both friends and strangers (separately) was calculated. This analysis indicated that DITF messages significantly increased compliance over a small request for both friends, uncorrected $\chi^{2}(1)=18.12, p<.001$, and strangers, uncorrected $\chi^{2}(1)=19.74, p<.001$. For strangers, the size of the initial request did not function as a moderating variable (compliance was 50\% for both moderate and large). Next, in order to examine if the DITF, large initial request, stranger condition exhibited the largest increase in compliance (as predicted in $\mathrm{H} 1$ ) or if the largest increase was with friends receiving a DITF message (H2) multiple $t$-tests between percentages were calculated. "Statpac," a statistical analysis package, was used to calculate t-tests between independent percentages. However, the package will not allow for testing percentages over 100\%; therefore, our analysis is conservative. First, we assessed if there was any statistical difference between friends receiving a DITF with a large initial request and a DITF with a moderate initial request. There was no difference, $t(40)=0.83, p=.21$, one-tailed; which supports the notion that initial request size does not moderate DITF effectiveness for friends. Next, we assessed $\mathrm{H} 1$ and $\mathrm{H} 2$ by comparing whether strangers receiving a DITF with a large initial request had a larger increase in compliance than friends who received a DITF with a large initial request. The difference was statistically significant, $t(41)=1.82$, $p=.04$, one-tailed. We understand that statistically, if the difference between $87 \%$ and $100 \%$ is statistically significant than the difference between $87 \%$ and $121 \%$ would certainly be statistically significant. ${ }^{8}$ These data indicate that the largest increase in compliance from a small request only is for strangers receiving a DITF message regardless of request size. This is only partially consistent with $\mathrm{H} 1$ because initial request size did not moderate the effect. These data are not consistent with H2. The next question to be answered is: Why does compliance vary in this manner?

Hypotheses 3 and 4 regard the reciprocal concessions explanation for DITF. According to reciprocal concessions, request type, relational familiarity, and initial request size will interact to affect perceptions such that when the request type is DITF, the initial request size is large, and the receiver is a stranger, both (a) perceptions that the request is a negotiation and (b) feelings of obligation will be greatest. Moreover, DITF message effectiveness should be mediated by (a) perceptions of obligation and (b) the perception that the request is a negotiation. 
Table 1 Means (and Standard Deviations) of the Dependent Variables as a Function of the Experimental Inductions

\begin{tabular}{|c|c|c|c|c|c|c|c|c|c|c|}
\hline & \multicolumn{4}{|c|}{ Friend } & \multirow[b]{3}{*}{$\begin{array}{c}\text { Small } \\
\text { only } \\
n=33\end{array}$} & \multicolumn{4}{|c|}{ Stranger } & \multirow[b]{3}{*}{$\begin{array}{c}\text { Small } \\
\text { only } \\
n=31\end{array}$} \\
\hline & \multicolumn{2}{|c|}{ Initial request only } & \multicolumn{2}{|c|}{ DITF } & & \multicolumn{2}{|c|}{ Initial request only } & \multicolumn{2}{|c|}{ DITF } & \\
\hline & $\begin{array}{c}\text { Mod } \\
n=26\end{array}$ & $\begin{array}{l}\text { Large } \\
n=27\end{array}$ & $\begin{array}{c}\text { Mod } \\
n=23\end{array}$ & $\begin{array}{l}\text { Large } \\
n=19\end{array}$ & & $\begin{array}{c}\text { Mod } \\
n=26\end{array}$ & $\begin{array}{l}\text { Large } \\
n=25\end{array}$ & $\begin{array}{l}\text { Mod } \\
n=22\end{array}$ & $\begin{array}{l}\text { Large } \\
n=24\end{array}$ & \\
\hline $\begin{array}{l}\% \text { complied } \\
\text { ( } \text { of yes's) }\end{array}$ & $\begin{array}{l}23.1 \% \\
(6)\end{array}$ & $\begin{array}{l}0 \% \\
(0)\end{array}$ & $\begin{array}{l}69.6 \% \\
(16)\end{array}$ & $\begin{array}{l}73.7 \% \\
(14)\end{array}$ & $\begin{array}{l}39.4 \% \\
(13)\end{array}$ & $\begin{array}{l}0 \% \\
(0)\end{array}$ & $\begin{array}{l}4 \% \\
(1)\end{array}$ & $\begin{array}{l}50 \% \\
(11)\end{array}$ & $\begin{array}{l}50 \% \\
(12)\end{array}$ & $\begin{array}{l}22.6 \% \\
(7)\end{array}$ \\
\hline $\begin{array}{l}\% \text { increase in } \\
\text { change compared } \\
\text { to baseline }\end{array}$ & N/A & N/A & $77 \%$ & $87 \%$ & baseline & N/A & N/A & $121 \%$ & $121 \%$ & baseline \\
\hline Negotiation & $27(1.09)$ & $2.77(1.14)$ & $.63(1.37)$ & $3.74(1.28)$ & $75(1.14)$ & $2.54(0.98)$ & $2.83(1.11)$ & $3.52(1.27)$ & $3.48(1.45)$ & $2.98(1.21)$ \\
\hline Obligation & $3.26(1.60)$ & $2.70(1.17)$ & $3.64(1.58)$ & $3.63(1.52)$ & $3.43(1.26)$ & $2.73(1.16)$ & $2.89(1.32)$ & $3.09(1.27)$ & $2.83(1.79)$ & $3.11(1.22)$ \\
\hline Helping & $4.16(1.39)$ & $3.94(1.40)$ & $4.45(1.18)$ & $4.62(.95)$ & $4.41(1.04)$ & $4.19(0.99)$ & $3.88(1.44)$ & $4.04(1.16)$ & $3.43(1.45)$ & $4.24(1.47)$ \\
\hline Guilt & $3.00(1.52)$ & $3.01(1.42)$ & $3.10(1.62)$ & $3.54(1.42)$ & $3.10(1.29)$ & $2.94(1.30)$ & $2.97(1.27)$ & $2.99(1.29)$ & $2.93(1.38)$ & $2.96(1.09)$ \\
\hline
\end{tabular}


Table 2 Zero Order Correlations Among the Variables

\begin{tabular}{|c|c|c|c|c|c|c|}
\hline & Req & Negotiation & Helping & Obligation & Guilt & Compliance \\
\hline Req & - & $.28^{\star *}$ & -.09 & .05 & .00 & $.49^{* *}$ \\
\hline Negotiation & $.21^{*}$ & - & .12 & $.29^{* *}$ & $.26^{* *}$ & .14 \\
\hline Helping & .17 & $.39^{\star *}$ & - & $.42^{\star \star}$ & $.44^{\star *}$ & .05 \\
\hline Obligation & .20 & $.26^{* *}$ & $.31^{\star *}$ & - & $.72^{\star *}$ & .14 \\
\hline Guilt & .09 & $.38^{\star \star}$ & $.39^{* *}$ & $.60^{\star \star}$ & - & .09 \\
\hline Compliance & $.53^{\star \star}$ & -.01 & .14 & $.34^{\star *}$ & .11 & - \\
\hline
\end{tabular}

The DITF variable is dummy coded such that initial request $=-1$, small request $=0$, and DITF $=1$. The bottom triangle includes correlations for friends and the top triangle includes correlations for strangers.

Req $=$ request type, coded such that higher values are more likely to be a DITF message.

${ }^{\star}$ significant at .05 (two-tailed), ${ }^{* *}$ significant at .01 (two-tailed).

To test Hypothesis 3, a full factorial $(3 \times 2 \times 2)$ ANOVA was computed examining these dependent variables as a function of the experimental manipulations. First, we examined perceptions that the request was a negotiation. There was no three-way interaction as predicted by reciprocal concessions. But, other interesting effects did emerge. There was a main effect for request type, $F(2,242)=17.40, p<.01, \eta^{2}=.07$, revealing that people are more likely to view a request as a negotiation when the request type is a DITF message $(M=3.33, S D=1.39)$ than when it is either an initial request only $(M=2.61, S D=1.09)$ or a small request only $(M=2.86, S D=1.17)$. There was also a main effect for initial request size, $F(1,242)=6.98, p<.01, \eta^{2}=$ .03. When the initial request is large it is seen more as a negotiation $(M=3.21, S D=$ $1.29)$ than it is with a moderate request $(M=2.71, S D=1.24)$. Finally, there was an interaction between relational familiarity and initial request size, $F(1,242)=3.81$, $p=.05, \eta^{2}=.03$ (see Figure 1). This interaction is important in that it suggests that strangers see the request as somewhat of a negotiation regardless of size of initial request. By contrast, the perception of friends seems strongly influenced by initial request size. Friends are more likely to view the request as a negotiation only when the initial request is large-regardless of message type. This latter finding is harmonious with the compliance data where compliance was also highest in these experimental conditions.

Feelings of obligation were also examined in the full $3 \times 2 \times 2$ ANOVA. Again, the predicted three-way interaction was not statistically significant. There was a main effect for request type, $F(2,242)=3.96, p<.05, \eta^{2}=.02$, revealing that people felt more obligated after a DITF message $(M=3.28, S D=1.57)$ or a small request $(M=$ $3.27, S D=1.24)$ than after an initial request alone $(M=2.89, S D=1.32)$. A main effect also emerged for relational familiarity, $F(1,242)=4.97, p<.05, \eta^{2}=.02$, revealing that people felt more obligated to friends $(M=3.31, S D=1.43)$ than they did to strangers $(M=2.94, S D=1.35)$. There were no interaction effects. These data provide mixed support for the reciprocal concessions model. Again, there was an absence of the predicted three-way interaction. 


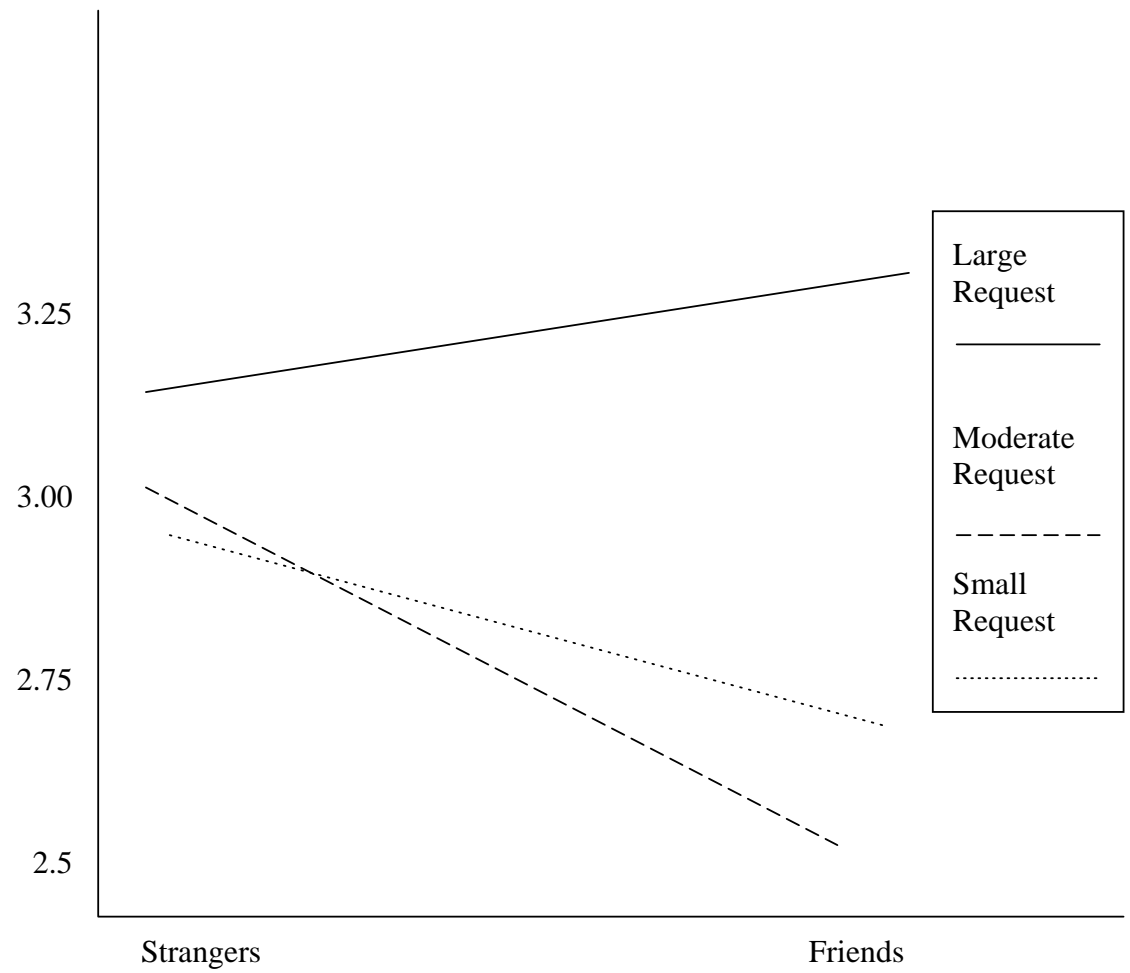

Figure 1 Line graph depicting the interaction between initial request size and relational familiarity on perceptions of a DITF sequential request as a negotiation.

Hypothesis 5 predicted that obligation and negotiation perceptions would mediate the DITF effect - if reciprocal concessions is the best fitting model. As previously mentioned the independent variable is request type and the dependent variable is donation size. This outcome variable provides more variance than the dichotomous variable "compliance," which is necessary for a multiple regression. The first equation, which regressed donation amount on request type, was significant at $R^{2}=.10, F(1,144)=16.05, p<.01$, and showed that the DITF message predicted increased compliance, $\beta=.32, t=4.01, p<.01$. These results replicate earlier analyses demonstrating support for the DITF effect in this study. The second equation, which regressed perceived negotiation on request type, reveals that the DITF message predicted increased negotiation perceptions, $R^{2}=.03, F(1,146)=4.44, p<.05, \beta=$ $.17, t=2.11, p<.05$. However, the third equation, regressing compliance on both request type and perceived negotiation, did not support the mediation model. Though the regression yielded $R^{2}=.13, F(2,139)=10.14, p<.01$, perceived negotiation did not predict increased donations, $\beta=-.09, t=-1.13, p>.05$, and the effect of the DITF manipulation on donations was not reduced by adding perceived negotiation to the regression equation, $\beta=.36, t=4.49, p<.01$. These statistical tests also failed to show obligation as mediator of donation amount. The first equation here replicates the very first equation for testing perceived negotiation 
as a mediator, and thus meets the first criteria for mediation. the second equation regressing obligation on request type was not significant, $R^{2}=.00, F(1,150)=0.00$, $p>.05, \beta=.00, t=0.2, p>.05$. Thus, mediation fails.

Hypotheses 5, 6, and 7 regard the social responsibility explanation for DITF effects. If the social responsibility model is the best fitting explanation for these data, relational familiarity will have a main effect on perceptions that the request is a helping situation such that friends will perceive the request as a helping situation more than will strangers. Additionally, this model suggests that feelings of guilt will be negatively correlated with compliance and DITF message effectiveness will be mediated by (a) perceptions that the request is a helping situation and (b) feelings of guilt.

Hypothesis 5 was tested with the full $(2 \times 3 \times 2)$ factorial ANOVA varying request type, initial request size, and relational familiarity. This analysis did produce the predicted main effect for familiarity on helping cognitions, $F(1,246)=4.39, p<.05$, $\eta^{2}=.02$, revealing that friends were more likely to perceive the request as a helping situation $(M=4.32, S D=1.21)$ than were strangers $(M=3.98, S D=1.33)$. No other main effects emerged. This is consistent with social responsibility. Interestingly, familiarity and request type interacted to influence helping perceptions, $F(1,246)=$ 4.44, $p<.05, \eta^{2}=.02$ (see Figure 2). This interaction indicates that, for strangers, the situation is viewed as one of helping when it is a small request, but not when it is a DITF request. Yet, with friends, the situation is viewed as helping when it is a DITF message as was expected.

Hypothesis 6 predicted that feelings of guilt and compliance would be positively correlated. A significant correlation was found, $r(N=252)=.11, p<.05$. These data are consistent with Hypothesis 6.

Hypothesis 7 argued that if the social responsibility model holds, then DITF message effectiveness is mediated by perceptions that the request is a helping situation and by feelings of guilt. Analyses testing perceived helping as a mediator of DITF effects were conducted on participants receiving the small request only and those receiving a moderate or large initial request followed by the smaller second request. Results do not support claims that the DITF effect on compliance is mediated by perceived helping. The first equation again replicates the one used to test negotiation and obligation as mediators, and thus meets the first criteria for mediation. In contrast to predictions, however, the second equation regressing helping on request type failed to show that the DITF manipulation predicted perceived helping, $R^{2}=.01, F(1,150)=1.01, p>.05, \beta=-.09, t=-1.04, p>.05$. Thus, mediation fails.

Following the analytical procedures above, a social responsibility account for guilt's role in mediating the DITF effect can be expressed as a set of equations examining DITF manipulation as the independent variable, compliance as the dependent variable, and experienced guilt as the mediating variable. When examining guilt as a function of DITF messages, these data fail to support O'Keefe and Figge's assertion that the DITF effect is mediated by guilt, $R^{2}=.01, F(1,147)=0.14, p>.05$, although our data does indicate that the two variables are correlated. For DITF, $\beta=.03$, 


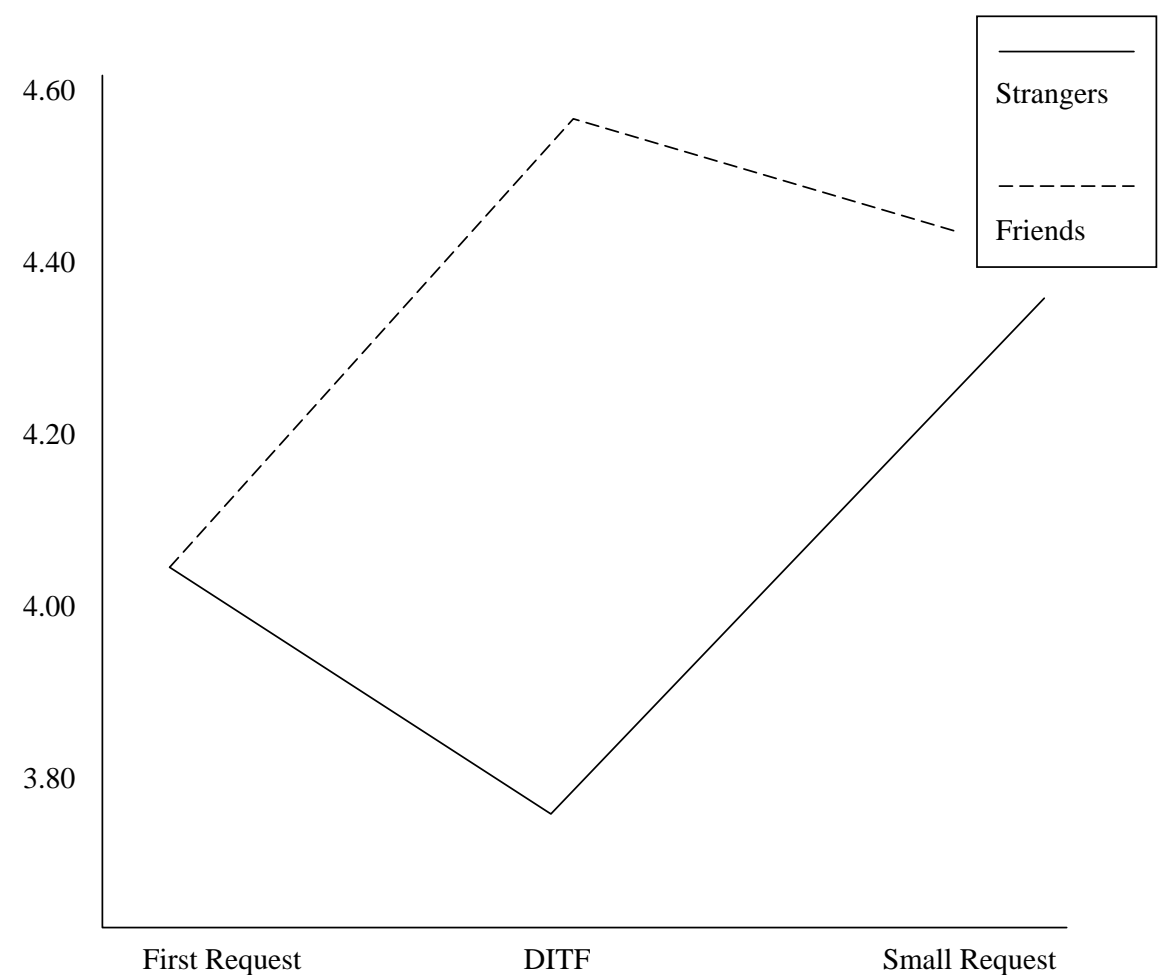

Figure 2 Line graph depicting the interaction between relational familiarity and request type on perceptions of a DITF sequential request as a helping situation.

$t=0.38, p>.05$. Regression run entering both DITF manipulation and guilt as predictors of willingness to donate yielded $R^{2}=.12, F(2,140)=9.11, p<.01$. Though these tests show that guilt predicts increased compliance, $\beta=.16, t=1.96$, $p<.05$, the effect of the DITF manipulation on compliance was not reliably reduced by adding guilt to the regression equation, $\beta=.29, t=3.66, p<.01$ (see Table 1 for means and standard deviations). Similarly, analyses run using guilt as the dependent variable and message type as the independent variable failed to the hypothesis that guilt is a mediating variable of the DITF effect, yielding $R^{2}=.00, F(1,188)=0.46$, $p>.05$. For location in sequence, $\beta=.05, t=0.68, p>.05$.

\section{Discussion}

This study began with several questions concerning the cognitive and affective mechanisms underlying the effectiveness of DITF messages. Of central interest was whether participants who received a DITF request (versus only the initial request or only the small request) would perceive the request as a helping experience (social responsibility) or a negotiation situation (reciprocal concessions). To test these theories against each other we manipulated the key moderating variables that would 
distinguish the theories as well as measured cognitive and affective reactions indicated by each model.

Based on extant literature, we forwarded seven predictions. Regarding compliance, it was argued that if the reciprocal concessions model is the best fitting explanation for these data, then the greatest increase in compliance would be found when a DITF request is delivered to a stranger and the size of the large initial request is greatest. But, if the social responsibility model is the best fitting explanation for these data, then the greatest increase in compliance would be found when the DITF is delivered to a friend (regardless of initial request size). We also made predictions regarding the cognitive and affective mediators presumed to underlie the reciprocal concessions as well as social responsibility models. We posited that if the reciprocal concessions model is the best fitting explanation for these data, request type, relational familiarity, and initial request size will interact to affect perceptions such that when the request type is DITF, the initial request size is large, and the receiver is a stranger, (a) perceptions that the request is a negotiation will be greatest and (b) feelings of obligation will be greatest. Moreover, we proposed that if the reciprocal concessions model is the best fitting explanation for these data, then DITF message effectiveness will be mediated by (a) the perception that the request is a negotiation, and (b) feelings of obligation. And, if the social responsibility model is the best fitting explanation for these data, relational familiarity will have a main effect on perceptions of the request as a helping situation such that friends will perceive the request as a helping situation more than strangers. The social responsibility model also holds that feelings of guilt will be positively correlated with compliance; DITF message effectiveness will be mediated by (a) perceptions that the request is a helping situation and (b) feelings of guilt.

These data suggest a different explanation, one that is based on the relationship between the receiver and the requestor. Overall, the data revealed that friends are more likely to comply than are strangers. These data also indicate that initial request size did not function as a moderating variable for either friends or strangers (with regard to the compliance data). We also found that for both friends and strangers DITF messages increased compliance as compared to a small request only; but, DITF messages lead to larger increases in compliance for strangers.

When examining the mediating variables, however, the picture became slightly muddled. These data were inconsistent with the predictions that any of these affective or cognitive measures mediated the relationship between the DITF message and compliance. That is, although the ANOVA data show that the moderating variables (request type, relational familiarity, initial request size) do affect the perceptual variables - they do not mediate the relationship between message and compliance. In fact, when examining the bivariate correlations among variables (Table 2) we see that the best predictor of compliance is whether the message is a DITF request.

These data were not perfectly consistent with either the social responsibility model or the reciprocal concessions model. Yet, the data from the ANOVA as well as inspection of the correlations among the variables (Table 2) provide some important information. One post hoc notion is that different theoretical processes occur for 
friends and strangers when they receive a DITF message. These data suggest that friends comply with DITF messages more due to feelings of obligation. Although we originally construed obligation as a key component of reciprocal concessions, it may indeed be relevant to perceiving a social responsibility. In fact, it may well be that laypersons understanding of obligation and scholars conception of obligation are quite different. Though, it should be noted that our data do indicate guilt and obligation to be separate factors. But, although strangers did report moderate perceptions of obligation, guilt, helping, and negotiation the variable that correlates most robustly with compliance (for strangers) is the request type. For friends, when the asker employed a DITF request (especially with a large initial request) perceptions that their friend was attempting to negotiate with them increased, which increased perceptions that they should help and that they would feel badly if they do not help. In turn, these feelings correlate to obligation to help one's friend, which is correlated with compliance.

For strangers, however, the variable most highly correlated with compliance is whether or not a DITF message was employed. Nonetheless, the bivariate correlations suggest that the message type did make the receiver perceive that a negotiation was occurring, which in turn increased feelings of obligation and guilt, and ultimately helping. But, none of these perceptions was highly correlated with increased compliance. The most important information to glean from these models is that unique and distinct perceptual processes underlying DITF effectiveness occur for friends and strangers. DITF is effective for both friends and strangers, but for entirely different reasons. Given that past DITF studies, aside from Tusing and Dillard (2000) who used hypothetical scenarios, have not varied relational familiarity it is not surprising that this moderator has not been explicitly discussed previously.

\section{Implications for DITF Research}

In some ways, the study here raises as many questions as it answers. In our attempt to distinguish between the most widely accepted current accounts for DITF effects, we provide evidence that partially support both models. Yet, it also appears that the best theoretical explanation for DITF may depend on the receiver of the message. Relational familiarity had a main effect with each of the outcome variables except negotiation perceptions. Instead, familiarity interacted with initial request size to affect perceived negotiation. Familiarity also interacted with request type to affect helping perceptions. It might be that when answering "Why does DITF work" that the answer is "It depends on who you are in relation to the asker."

If this is the case, and the findings are not the result of a Type I error, then relational characteristics need to be fully explored by compliance-gaining scholars. It may very well be the case that when people need to raise money for charities, such as is the case with schoolchildren, Girl Scouts, and others; they turn to their family and friends first. Yet, most of the extant DITF data regards strangers. Certainly, it is important that we truly understand the theoretical rationale for complying to a DITF message for either audience. Until now it appears that scholars thought the theory 
underlying DITF effectiveness did not depend on the relationship between the asker and the receiver. This study seriously challenges this assumption.

Finally, it might be that neither the reciprocal concessions model nor socialresponsibility model accounts for the DITF effect. Instead, perhaps compliancegaining scholars should rethink the notion that a singular explanation exists for the DITF effect. These data partially suggest that the negotiation model and the helping model operate together. For example, the correlation matrix shows that guilt and obligation are highly correlated, as are negotiation perceptions and feelings of guilt. Future research in this area is certainly mandated. The present study highlights the existing relationships among several theoretical mechanisms thought responsible for the DITF phenomena, and shows their independent impact on compliance to requests for help.

\section{Notes}

[1] Another theoretical explanation that has been advanced is perceptual contrast. It does seem, however, that most scholars reject this theory based on the extant data (Cantrill \& Seibold, 1986). The reciprocal concessions and social responsibility explanations are still being debated, which is why they are tested in this investigation.

[2] Gouldner (1960) clarified several types of reciprocity: heteromorphic versus homomorphic reciprocity, positive versus negative reciprocity, and altruistic versus egoistic reciprocity. In heteromorphic reciprocity, a person returns a good or service received from another person with a different good or service of equal value, often referred to as "tit-for-tat." In the case of homomorphic reciprocity, a good or service is paid back by the same good or service, often referred to as "tat-for-tat." Reciprocity also can be positive or negative. Positive reciprocity means that good deeds are reciprocated with positive returns. Negative reciprocity refers to negative sanctioning of norm violators. Gouldner further distinguished egoistic reciprocity, or reciprocating for future benefits, from altruistic reciprocity, or reciprocating with no apparent future returns.

[3] Notably, Bell et al. (1996) did not find a main effect of request type (DITF versus control) on feelings of obligation. Nonetheless, this variable is posited to mediate the DITF effect if the negotiation model is correct.

[4] Two other moderating variables - same or different requestor and prosocialness of the request-are often varied in DITF studies. These variables are controlled for in this experiment by holding them constant.

[5] However, these results do not suggest that people do not follow the principle of reciprocity in close relationships. Reciprocity, as a justice principle, has been shown to be a robust and powerful force governing human exchanges in many situations including both repeated and unrepeated interactions. People are equally unsatisfied when they give more than they receive and when they receive more than they give (Walster, Walster, \& Berscheid, 1978). They also become resentful or feel a sense of betrayal when their requests are not granted by friends or they are asked to contribute too much (e.g., O'Connor, 1992; Walker, 1995; Winn et al., 1991). An explanation for these incompatible observations may be that people expect from friends and strangers different patterns of reciprocity. Long-term reciprocity is proposed in this paper as the pattern of reciprocity adopted among friends. With limited energy and resources, people may choose to be benevolent only in their communal relationships with kin and friends: They obscure their own contributions, they avoid overt monitoring of their friends' contributions, and they do not demand immediate and exact reciprocation. However, they may be expecting their friends to provide emotional support in return 
instead of exact material benefits, and they may want to preserve the right to make a request in the future when they most need it instead of receiving immediate reciprocation from their friends. In other words, a rough balance of giving and receiving on a large timescale, longterm reciprocity, may work in close relationships such as friendships.

[6] In the large request condition, "through the end of April" represented a nearly eight month commitment.

[7] Given the robust correlation between guilt and obligation $(r=.66, p<.05)$ we wanted to rule out the possibility that these two variables were actually one factor. Therefore, another CFA was conducted with only these two factors. The CFA was testing the prediction that these two scales made a two-factor model. If the data support a one-factor model, then this will be indicated in the goodness of fit indices. These data did indicate that the two-factor model was an excellent fit, $\chi^{2}(26)=115.14, p<.05$, GFI $=.91$, RMSEA $=.12$. Therefore, these variables are highly correlated, but they are distinct factors.

[8] In order to compare these four ratios the correct statistical computation would have had to account for the variability in both the numerator and the denominator. After numerous discussions with statistical experts at Yale University (L. Liu, personal communication, April 26, 2007), Iowa State University (P. Dixon, personal communication, April 26, 2007), and the University of Maryland (E. Fink, personal communication, April 24, 2007), we came to the conclusion that there is not an appropriate statistic for such a comparison. Therefore, we reported the $t$-test between independent percentages because it provides the closest test. In addition, although the highest percentage that can be entered into that equation is 100; we reiterate that this provides a more conservative estimate.

\section{References}

Abrahams, M. F., \& Bell, R. A. (1994). Encouraging charitable contributions: An examination of three models of door-in-the-face compliance. Communication Research, 21, 131-153.

Baron, R. M., \& Kenny, D. (1986). The moderator-mediator variable distinction in social psychological research: Conceptual, strategic, and statistical considerations. Journal of Personality and Social Psychology, 51, 1173-1182.

Bar-Tal, D., Bar-Zohar, Y., Greenberg, M. S., \& Hermon, M. (1977). Reciprocity behavior in the relationship between donor and recipient and between harm-doer and victim. Sociometry, 40, 293-298.

Bell, R. A., Abrahams, M. F., Clark, C. L., \& Schlatter, C. (1996). The door-in-the-face compliance strategy: An individual differences analysis of two models in an AIDS fundraising context. Communication Quarterly, 44, 107-124.

Berkowitz, L., \& Daniels, L. (1963). Responsibility and dependency. Journal of Abnormal and Social Psychology, 66, 429-436.

Boster, F. J., Mitchell, M. M., Lapinski, M. K., Orrego, V. O., Cooper, H., \& Reinke, R. (1999). The impact of guilt and type of compliance-gaining message on helping behavior. Communication Monographs, 66, 168-177.

Boster, F. J., Rodriguez, J. I., Cruz, M. G., \& Marshall, L. (1995). The relative effectiveness of a direct request message and a pregiving message on friends and strangers. Communication Research, $22,475-484$.

Burger, J. M., Soroka, S., Gonzago, K., Murphy, E., \& Somervell, E. (2001). The effect of fleeting attraction on compliance to requests. Personality and Social Psychology Bulletin, 27, 15781586.

Cann, A., Sherman, S. J., \& Elkes, R. (1975). Effects of first request size and timing of a second request on compliance: The foot in the door and the door in the face. Journal of Personality and Social Psychology, 32, 774-782. 
Cantrill, J. G., \& Seibold, D. R. (1986). The perceptual contrast explanation of sequential request strategy effectiveness. Human Communication Research, 13, 253-267.

Chertkoff, J. M., \& Conley, M. (1967). Opening offer and frequency of concession as bargaining strategies. Journal of Personality and Social Psychology, 7, 185-193.

Cialdini, R. B. (1984). Influence. New York: William Morrow.

Cialdini, R. B. (1993). Influence: Science and Practice (pp. 21-22). New York: Harper Collins.

Cialdini, R. B., \& Ascani, K. (1976). Test of a concession procedure for inducing verbal, behavioral, or further compliance with a request to give blood. Journal of Applied Psychology, 61, 295300 .

Cialdini, R. B., \& Trost, M. R. (1998). Social influence: Social norms, conformity, and compliance. In D. T. Gilbert, S. T. Fiske, \& G. Lindzey (Eds.), Handbook of social psychology (Vol. 2, 4th ed., pp. 151-192). Boston: McGraw-Hill.

Cialdini, R. B., Vincent, J. E., Lewis, S. K., Catalan, J., Wheeler, D., \& Darby, B. L. (1975). Reciprocal concessions procedure for inducing compliance: The door-in-the-face technique. Journal of Personality and Social Psychology, 31, 206-215.

Clark, M. S. (1981). Noncomparability of benefits given and received: A cue to the existence of friendship. Social Psychology Quarterly, 44, 375-381.

Clark, M. S., \& Mills, J. (1979). Interpersonal attraction in exchange and communal relationships. Journal of Personality and Social Psychology, 37, 2-24.

Clark, M. S., Ouellette, R., Powell, M. C., \& Milberg, S. (1987). Recipient's mood, relationship type, and helping. Journal of Personality and Social Psychology, 53, 94-103.

Diekmann, A. (2004). The power of reciprocity: Fairness, reciprocity, and stakes in variants of the dictator game. Journal of Conflict Resolution, 48, 487-505.

Dillard, J. P. (1991). The current status of research on sequential-request compliance techniques. Personality and Social Psychology Bulletin, 17, 283-288.

Dillard, J. P., \& Hale, J. L. (1992). Prosocialness and sequential request compliance techniques: Limits to the foot-in-the-door and the door-in-the-face? Communication Studies, 43, 220 232.

Dillard, J. P., Hunter, J. E., \& Burgoon, M. (1984). Sequential-request persuasive strategies: Metaanalysis of foot-in-the-door and door-in-the-face. Human Communication Research, 10, 461-488.

Fehr, E., \& Gächter, S. (2000). Fairness and retaliation: The economics of reciprocity. Journal of Economic Perspectives, 14, 159-181.

Fern, E. F., Monroe, K. B., \& Avila, R. A. (1986). Effectiveness of multiple request strategies: A synthesis of research results. Journal of Marketing Research, 23, 144-152.

Frenzen, J. K., \& Davis, H. L. (1990). Purchasing behavior in embedded markets. Journal of Consumer Research, 17, 1-12.

Goldman, G., McVeigh, J. F., \& Richterkessing, J. L. (1984). Door-in-the-face procedure: Reciprocal concession, perceptual contrast or worthy person. Journal of Social Psychology, 123, 245-251.

Gouldner, A. W. (1960). The norm of reciprocity: A preliminary statement. American Sociological Review, 25, 161-178.

Güth, W., Schmittberger, R., \& Schwarze, B. (1982). An experimental analysis of ultimatum bargaining. Journal of Economic Behavior and Organization, 3, 367-388.

Hale, J. J., \& Laliker, M. (1999). Explaining the door-in-the-face: Is it really time to abandon reciprocal concessions? Communication Studies, 10, 203-210.

Komorita, S. S., \& Brenner, A. R. (1968). Bargaining and concession making under bilateral monopoly. Journal of Personality and Social Psychology, 9, 15-20.

Langer, E., Blank, A., \& Chanowitz, B. (1978). The mindlessness of ostensibly thoughtful action: The role of "placebic" information in interpersonal interaction. Journal of Personality and Social Psychology, 36, 635-642.

Langer, E. J. (1989). Mindfulness. Reading, MA: Addison-Wesley. 
Mowen, J. C., \& Cialdini, R. B. (1980). On implementing the door-in-the-face compliance technique in a business context. Journal of Marketing Research, 27, 253-258.

O'Connor, P. (1992). Friendships between women: A critical review. New York: Guilford Press.

O'Keefe, D. J. (1999). Three reasons for doubting the adequacy of the reciprocal concessions explanation of door-in-the-face effects. Communication Studies, 50, 211.

O'Keefe, D. J., \& Figge, M. (1997). A guilt-based explanation of the door-in-the-face influence strategy. Human Communication Research, 24, 64-81.

O'Keefe, D. J., \& Figge, M. (1999). Guilt and expected guilt in the door-in-the-face technique. Communication Monographs, 66, 312-324.

O'Keefe, D. J., \& Hale, S. L. (1998). The door-in-the-face influence strategy: A random-effects metaanalytic review. Communication Yearbook, 21, 1-33.

Patch, M. E., Hoang, V. R., \& Stahelski, A. J. (1997). The use of metacommunication in compliance: Door-in-the-face and single-request strategies. Journal of Social Psychology, 137, 88-92.

Pratkanis, A. R., \& Aronson, E. (2001). Age of propaganda: The everyday use and abuse of persuasion. New York: Bedford, Freeman, \& Worth.

Reeves, R. A., Baker, G. A., Boyd, J. G., \& Cialdini, R. B. (1991). The door-in-the-face technique: Reciprocal concessions vs. self-presentational explanations. Journal of Social Behavior and Personality, 6, 345-558.

Rook, K. S. (1987). Reciprocity of social exchange and social satisfaction among older women. Journal of Personality and Social Psychology, 52, 145-154.

Shackelford, T. K., \& Buss, D. M. (1996). Betrayal in mateships, friendships, and coalitions. Personality and Social Psychology Bulletin, 22, 1151-1164.

Tusing, K. J., \& Dillard, J. P. (2000). The psychological reality of the door-in-the-face: It's helping, not bargaining. Journal of Language and Social Psychology, 19, 5-25.

Walker, K. (1995). "Always there for me:" Friendship patterns and expectations among middle- and working-class men and women. Sociological Forum, 10, 273-296.

Wallace, J., \& Sadalla, E. (1966). Behavioral consequences of transgression: I. The effects of social recognition. Journal of Experimental Research in Personality, 1, 187-194.

Walster, E., Walster, W., \& Berscheid, E. (1978). Equity: Theory and research. Boston: Allyn \& Bacon, Inc.

Williamson, G. M., \& Clark, M. S. (1992). Impact of desired relationship type on affective reactions to choosing and being required to help. Personality and Social Psychology Bulletin, 18, 10-18.

Williamson, G. M., Clark, M. S., Pegalis, L. J., \& Behan, A. (1996). Affective consequences of refusing to help in communal and exchange relationships. Personality and Social Psychology Bulletin, 22, 34-47.

Winn, K. I., Crawford, D. W., \& Fischer, J. (1991). Equity and commitment in romance versus friendship. Journal of Social Behavior and Personality, 6, 301-314. 
Copyright of Communication Monographs is the property of National Communication Association and its content may not be copied or emailed to multiple sites or posted to a listserv without the copyright holder's express written permission. However, users may print, download, or email articles for individual use. 